\title{
Discharge of a Triangular Orifice under Free Flow Conditions
}

\author{
Anna Sosnowska \\ Faculty of Building Services, Hydro and Environmental Engineering, Warsaw University of Technology, \\ Poland, ul. Nowowiejska 20, 00-653 Warszawa, e-mail: anna.sosnowska@pw.edu.pl
}

(Received March 02, 2021; revised June 07, 2021)

\begin{abstract}
In this paper, flow through a free triangular orifice is considered. The comparison of two formulas was conducted for discharge calculations: a large orifice formula and a small orifice formula. The results show that, above a certain value of upstream head to orifice height ratio there is no need for small-large formula discrimination. The differences in the outcomes for the two formulas are negligible for upstream head to orifice height ratios greater than 3 . This means that a small orifice formula can be used instead of a large orifice formula. Calculations were performed for different variants of triangle orientation (with tip downwards, sidewards and upwards) as well as for different dimensions of orifice (equilateral and isosceles). The calculations also included different submergence levels of the upper edge of the orifice and variable dimensions of the orifice with constant upstream head. Neither of these conditions affect the relative deviation values for small and large orifice formulas.
\end{abstract}

Key words: orifice; orifice equation; discharge

\section{Introduction}

Weirs, orifices and sluice gates are widely used in irrigation networks for distributing water from the source to irrigated areas (Vatankhah and Mirnia 2018). Orifices are also commonly used flow control and metering devices (Shammaa et al 2005). When the orifice discharges into the air (as presented in Fig. 1) it is known as free. Traditionally, free orifices are classified as small or large, depending on the height of the orifice and the upstream head. For very low upstream head values, the pressure profile cannot be uniformly formed through the orifice cross section and a large orifice condition occurs (Vatankhah and Bijankhan 2013). The theoretical discharge equation for a large orifice requires analytical integration. As the upstream head increases, pressure variation across the orifice can be neglected and a simple discharge equation for a small orifice can be applied.

(C) 2021 Institute of Hydro-Engineering of the Polish Academy of Sciences. This is an open access article licensed under the Creative Commons Attribution-NonCommercial-NoDerivs License (http://creativecommons.org/licenses/by-nc-nd/3.0/). 
In engineering practice, it is important to establish the conditions in which the large-orifice effect is significant. Despite the several studies that have been carried out on free orifices, triangular orifices are rarely investigated. Previous work on this topic (Kubrak 2015) has been limited to the analysis of flow conditions for circular orifices. In this paper, vertical, sharp-crested triangular orifices under free flow conditions are studied analytically. The aim of this study is to determine for what values of upstream head, in relation to the orifice height, the small orifice formula for calculating discharge can be applied.

\section{Discharge Equations}

A vertical orifice may be classified based on its discharge conditions. Three types of orifice flow can be distinguished: free, partially submerged and fully submerged. In this study, the discharge of an isosceles triangular orifice under free flow conditions was investigated. Considerations include a triangular orifice that is positioned with its tip upwards, tip downwards and tip to the side (Fig. 1).

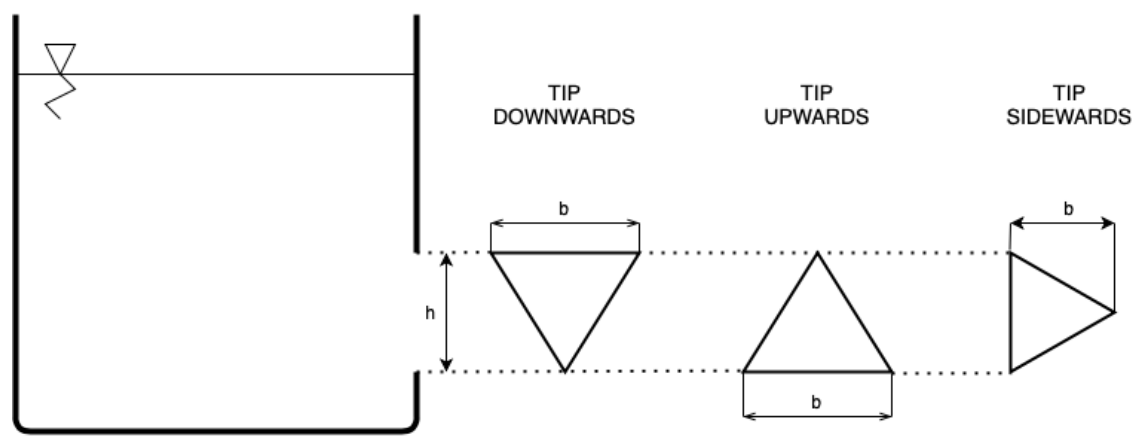

Fig. 1. Orientation of the triangular orifices in the research

For a steady flow through an orifice, flow velocity and, therefore, flow discharge is constant. The formula for calculating this discharge can be derived from Bernoulli's theorem between a fluid free surface and the orifice. Two types of orifices have been distinguished: small and large. In engineering practice, it is stated that an orifice can be defined as being large if the relation of the orifice height to the submergence of the orifice's centre of gravity is greater than 0.1 (Mitosek 2020).

\subsection{Small Orifice}

For a small orifice, the velocity of the flowing liquid is assumed to be constant in every point of the orifice's area. The standard equation that can be used to calculate the discharge through a small triangular orifice can be written as (Smith and Walker 1923): 


$$
Q=\mu A \sqrt{2 g H},
$$

where:

$$
\begin{aligned}
& \mu-\text { coefficient of discharge, } \\
& A-\text { area of the orifice, } \\
& H-\text { height of the free surface of liquid above the centreline of the orifice. }
\end{aligned}
$$

\subsection{Large Orifice}

In a large orifice, the velocity of liquid flowing through the orifice varies over the entire cross section, due to significant variations in upstream head values relating to various points in the cross section of the orifice. The calculation of the discharge is based on the division of the orifice area into elemental horizontal strips with a thickness of $d z$. Then, each strip can be assumed to be a small orifice and the elemental discharge can be calculated according to Eq. (1). Total discharge for a large orifice has to be determined by integrating the discharges through elemental strips:

$$
Q=\mu \sqrt{2 g} \int y(z) \sqrt{z} d z
$$

where:

$$
y(z)-\quad \text { width of the elemental strip. }
$$

As mentioned before, three positions of triangular orifices were analysed in this paper: with tip downwards, upwards and sidewards. In further considerations, discharge equations for each position were denoted by subscripts " $d$ ", " $u$ " and " $s$ " respectively.

For the first case, orifice division into elemental strips is shown in Fig. 2.
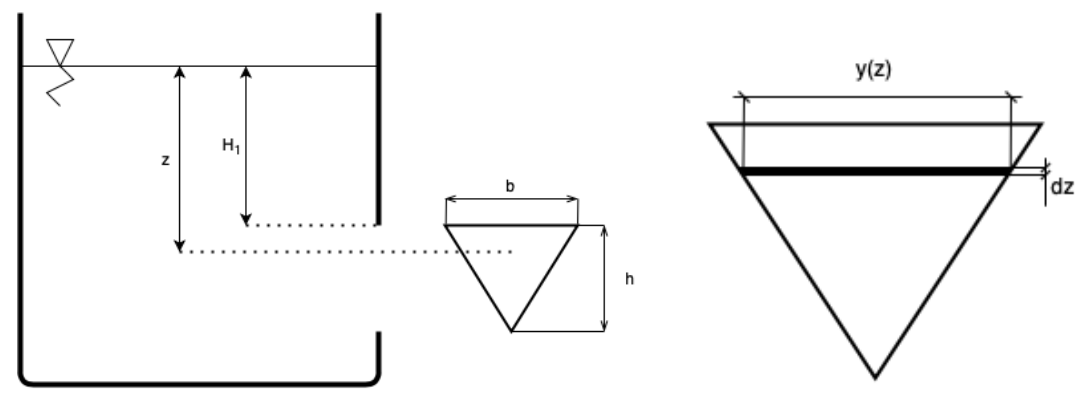

Fig. 2. Division of the tip downwards triangle into elemental strips 
The principle of triangle similarity allows us to determine that the width of an elemental strip equals:

$$
\begin{gathered}
\frac{b}{h}=\frac{y(z)}{H_{1}+h-z}, \\
y(z)=\frac{b}{h}\left(H_{1}+h-z\right),
\end{gathered}
$$

Total discharge through a triangular orifice with tip orientated downwards is given by:

$$
Q_{d}=\mu \sqrt{2 g} \int_{H_{1}}^{H_{1}+h} \frac{b}{h}\left(H_{1}+h-z\right) z^{1 / 2} d z .
$$

For the triangle with tip upwards, the division into elemental strips is shown in Fig. 3.
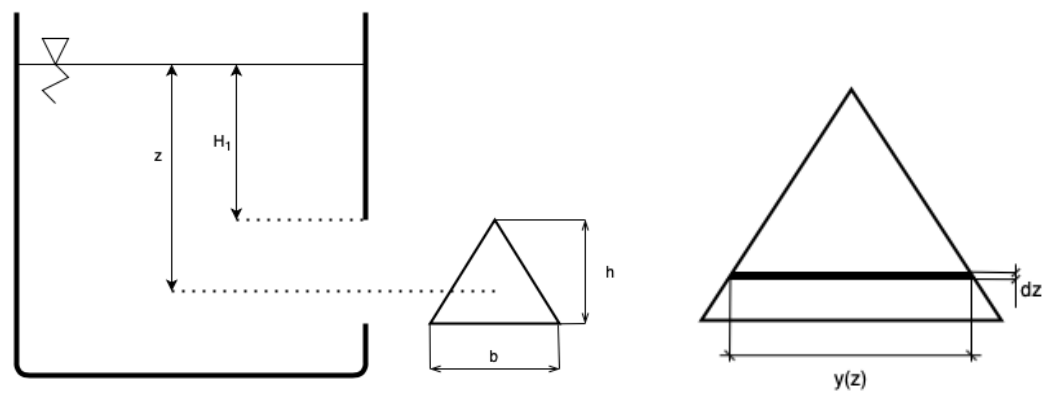

Fig. 3. Division of the tip upwards triangle into elemental strips

Again, the principle of triangle similarity allows us to determine the width of an elemental strip:

$$
\begin{gathered}
\frac{b}{h}=\frac{y(z)}{z-H_{1}}, \\
y(z)=\frac{b}{h}\left(z-H_{1}\right) .
\end{gathered}
$$

Total discharge through a triangular orifice with tip orientated upwards is given by:

$$
Q_{u}=\mu \sqrt{2 g} \int_{H_{1}}^{H_{1}+h} \frac{b}{h}\left(z-H_{1}\right) z^{1 / 2} d z
$$


To calculate discharge through a triangular orifice with tip orientated sidewards, it was divided into two parts, see Figs. 4 and 5.
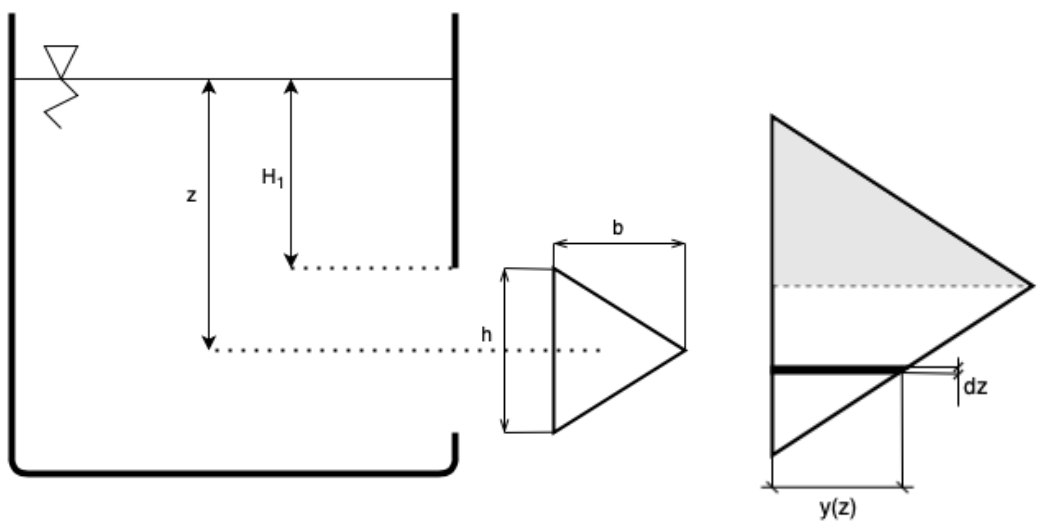

Fig. 4. Division of the tip sidewards triangle into elemental strips, first part

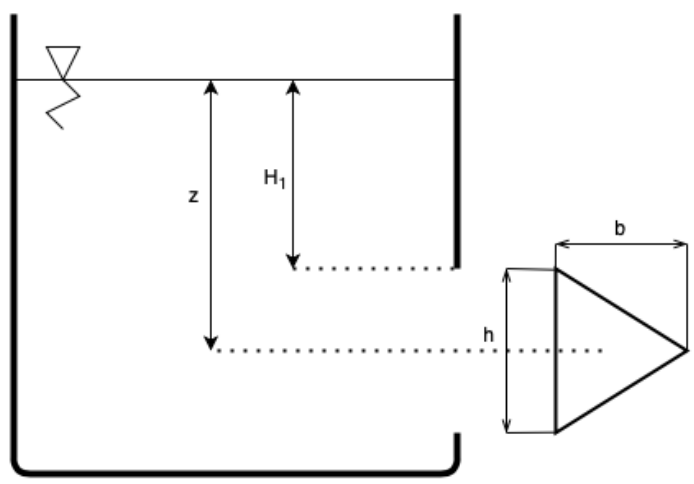

$y(z)$

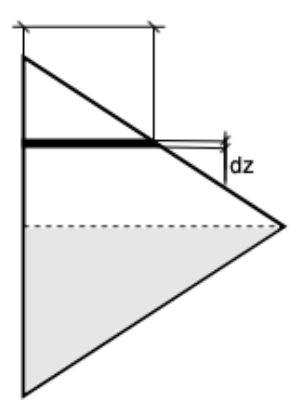

Fig. 5. Division of the tip sidewards triangle into elemental strips, second part

For $z \in\left\langle H_{1} ; H_{1}+\frac{h}{2}\right\rangle$

$$
\begin{gathered}
\frac{h}{b}=\frac{z-H_{1}}{y(z)}, \\
y(z)=\frac{2 b}{h}\left(z-H_{1}\right) .
\end{gathered}
$$

Discharge through the first part of an orifice with tip sidewards is equal to: 


$$
Q_{s_{1}}=\mu \sqrt{2 g} \int_{H_{1}}^{H_{1}+\frac{h}{2}} \frac{2 b}{h}\left(z-H_{1}\right) z^{1 / 2} d z .
$$

For $z \in\left\langle H_{1}+\frac{h}{2} ; H_{1}+h\right\rangle$

$$
\begin{gathered}
\frac{h}{b}=\frac{H_{1}+h-z}{y(z)}, \\
y(z)=\frac{2 b}{h}\left(H_{1}+h-z\right) .
\end{gathered}
$$

Discharge through the second part of an orifice with tip sidewards is equal to:

$$
Q_{s_{2}}=\mu \sqrt{2 g} \int_{H_{1}+\frac{h}{2}}^{H_{1}+h} \frac{2 b}{h}\left(H_{1}+h-z\right) z^{1 / 2} d z .
$$

The total discharge through a triangular orifice with tip sidewards is the sum of the two above cases:

$$
Q_{s}=\mu \sqrt{2 g} \int_{H_{1}}^{H_{1}+\frac{h}{2}} \frac{2 b}{h}\left(z-H_{1}\right) z^{1 / 2} d z+\mu \sqrt{2 g} \int_{H_{1}+\frac{h}{2}}^{H_{1}+h} \frac{2 b}{h}\left(H_{1}+h-z\right) z^{1 / 2} d z .
$$

\section{Comparison of Formulas for Small and Large Orifices}

Calculations of orifice outflow for various levels of submergence were performed. The identification of the differences between small and large orifice formulas was conducted according to the following variants:

variant 1: $\quad H_{1}=$ const and variable $h$ for different $b / h$ values variant 2: $\quad h=$ const and variable $H_{1}$ for different $b / h$ values variant 3: variable $H_{1}$ and variable $h$ for constant $b / h$ value

In the first variant, it was assumed that the upstream head was constant and equal to $1 \mathrm{~m}$. Dimensions of the orifice were changeable. The value of $h$ varied from 0.2 $\mathrm{m}$ to $10.0 \mathrm{~m}$. The calculations included different $b / h$ values: $0.500,1.000,1.155$ (an equilateral triangle), 1.500 and 2.000 .

The second variant presented the opposite situation. The height of the orifice $(h)$ was kept constant, equal to $1 \mathrm{~m}$, while the value of upstream head was changeable, varying from $0.1 \mathrm{~m}$ to $5.0 \mathrm{~m}$. Calculations were conducted for the same values of $b / h$ ratios as in the first variant. 
In the third variant, it was assumed that the $b / h$ ratio was constant and equal to 1 , while the values of $\mathrm{H} 1$ were changeable (from 0.1 to $2.0 \mathrm{~m}$ ) as well as the values of $h$ (from 1 to $10 \mathrm{~m}$ ). To compare the values of discharge obtained by using formulas for small and large orifices, for each variant and each type of orifice position, relative deviation values $\delta$ were calculated:

$$
\delta=\frac{Q_{\text {small }}-Q_{\text {large }}}{Q_{\text {small }}} \cdot 100 \%,
$$

where:

$Q_{\text {small }}$ - discharge calculated using Eq. (1),

$Q_{\text {large }}$ - discharge calculated using Eq. (5), (8) and (15).

The coefficient of discharge value may vary slightly depending on different dimensions of the orifice as well as different submergence level (Stefański and Wyszkowski 1972). However, it was assumed that, for a given $H_{1} / h$ ratio, the coefficient of discharge is constant and does not influence the method of calculation.

The calculation results are shown in Fig. 6 and Fig. 7, as a function of $H_{1} / h$.

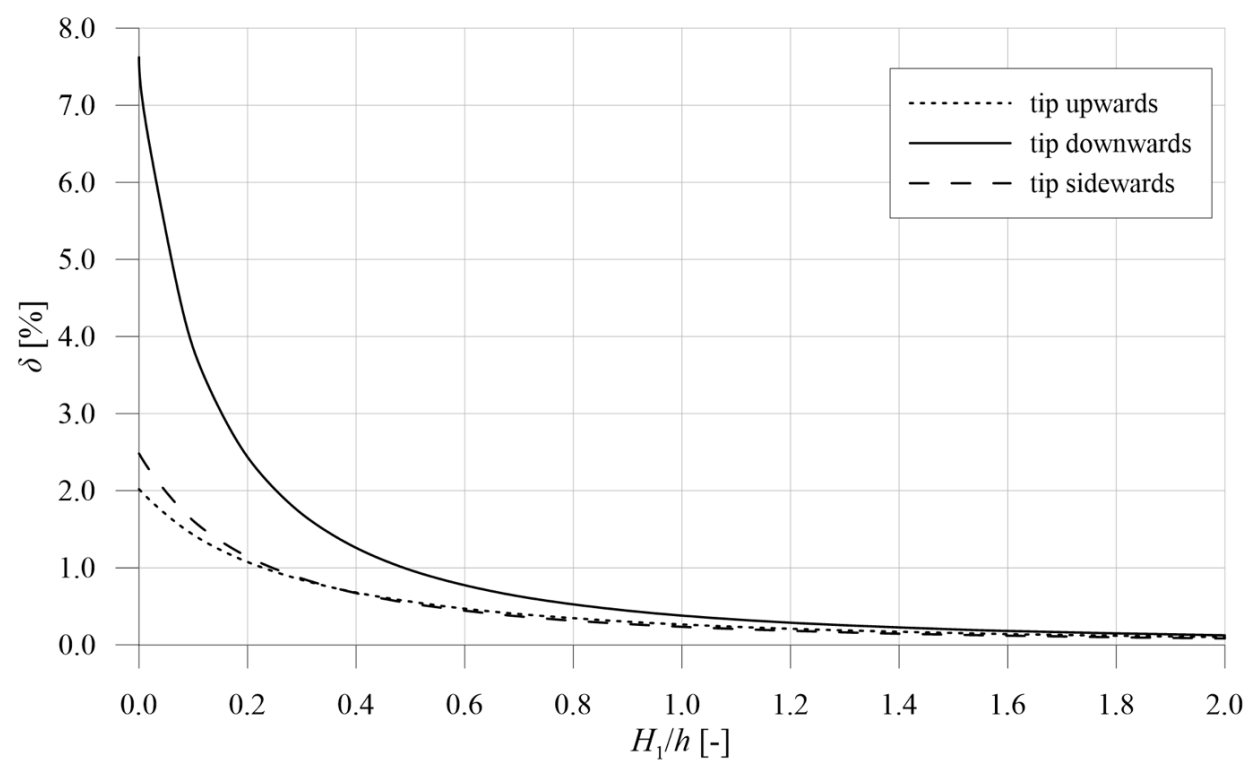

Fig. 6. Difference between large and small orifice formula, calculated according to variants 1 , 2 and 3 for a triangular orifice with tip upwards, downwards and sidewards

For all cases of calculation variants, the curves for each type of orifice orientation are concurrent (Fig. 6). In order to better illustrate this relationship, the diagram in Fig. 7 was constructed which presents the results for a triangular orifice with tip downwards for different calculation variants. It shows that all of the calculated points lie on the same curve. 


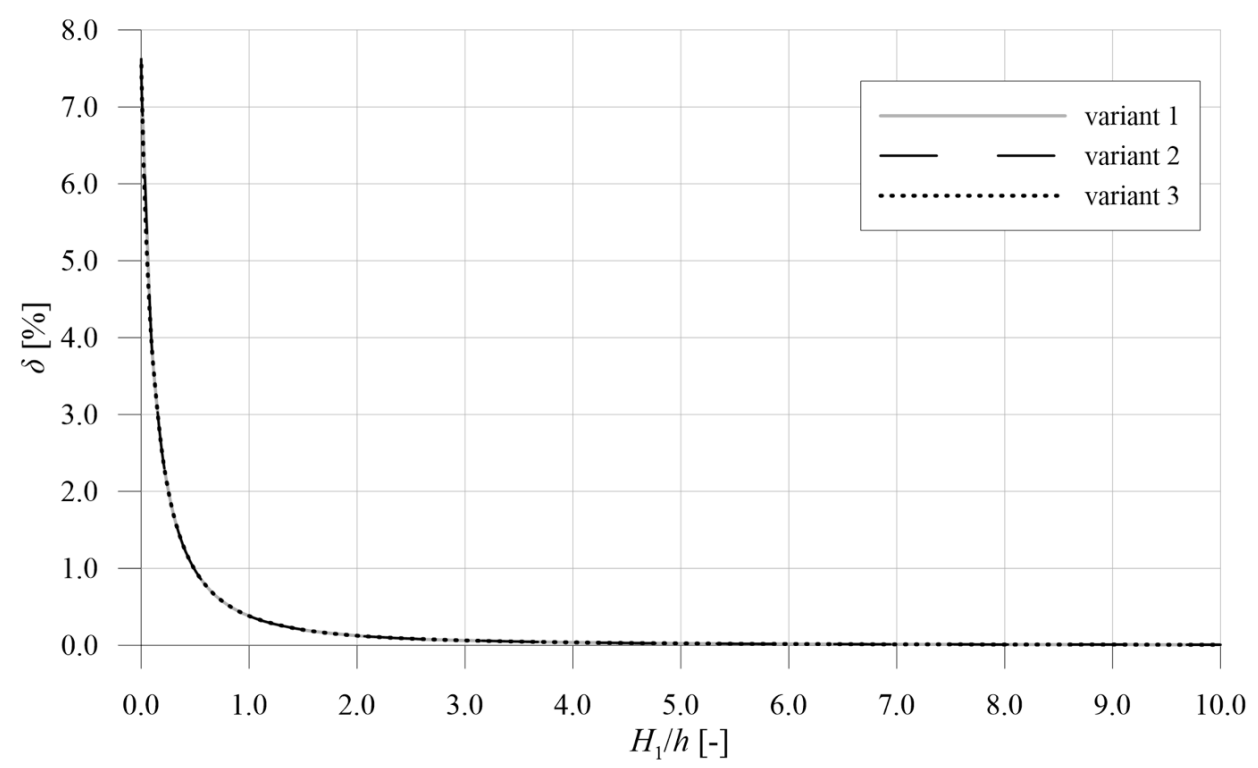

Fig. 7. The difference between large and small orifice formula for a triangular orifice with tip downwards calculated according to variants 1,2 and 3

The curves presented in Fig. 6 show that the differences between large and small orifice formulas for discharge calculations are small. In all types of orifice orientation, the relation decreases very quickly to very small values. In the case of a triangular orifice with tip upwards or sidewards, the differences between the small and large orifice formulas are very similar and oscillate around $2 \%$ for the smallest $H_{1} / h$ ratio, i.e. the smallest submergence of the orifice. For a triangular orifice with tip downwards the biggest difference is over 7\%. In all three cases, an increase in submergence level of the orifice causes a decrease in the relative deviation value. For $H_{1} / h$ ratio greater than 3 , the calculation error is around $0.05 \%$ and can be negligible.

\section{Discharge Values Depending on the Orifice Orientation}

A comparison of the discharge calculations for different orifice orientations was also performed, to check the correctness of the methods used. The results are shown on the graph in Fig. 8. Discharge ratios were calculated with respect to the flow value for the triangle with tip upwards. The discharge values were calculated assuming that the dimensions of the orifice ( $b$ and $h$ ) are the same for each orientation type.

The flow through a triangular orifice that is orientated with its tip upwards has the biggest value, while a triangular orifice with tip sidewards results in the smallest value of discharge. The differences between flow values decrease with the $H_{1} / h$ ratio, i.e. with increasing orifice submergence. For $H_{1} / h$ ratios higher than 10 , the discharge ratio remains fairly constant which means that the discharge value is no longer affected by the increase in orifice submergence level. 


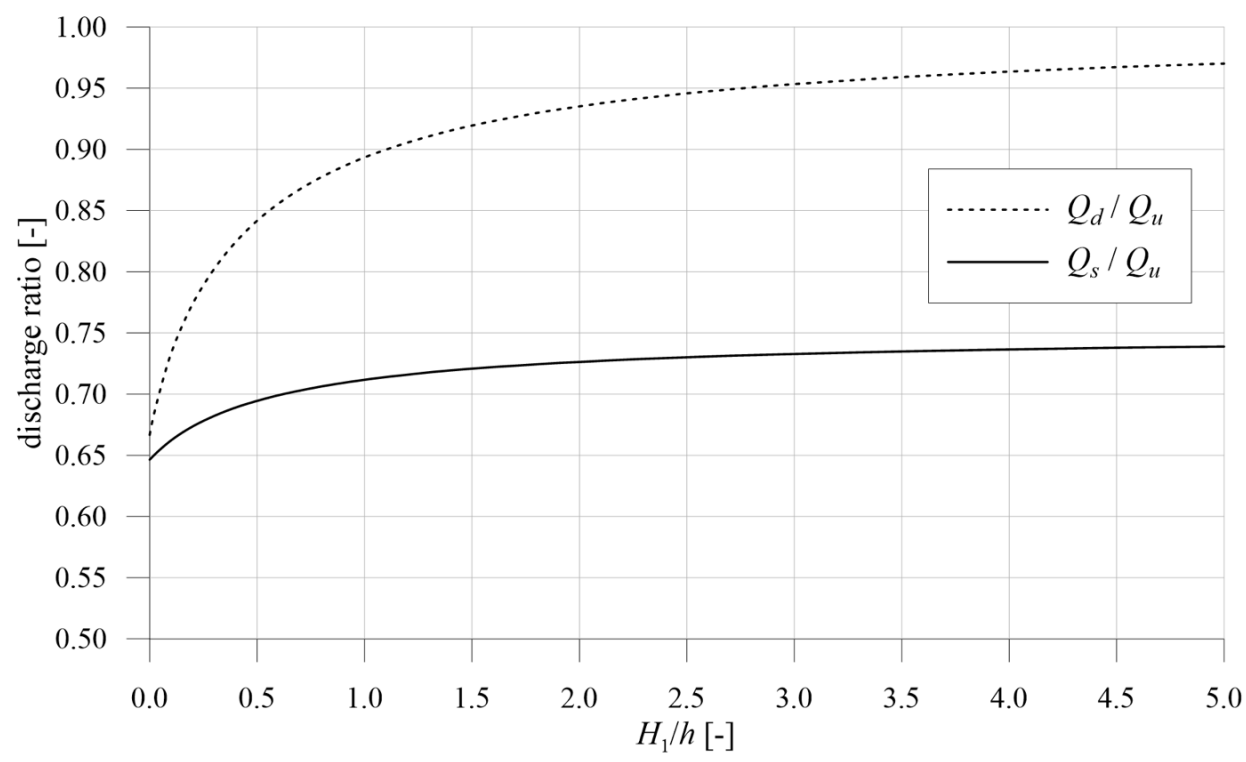

Fig. 8. Comparison of discharge value depending on the orifice's orientation, where: $Q_{d}-$ discharge value for an orifice with tip downwards, $Q_{s}$ - discharge value for an orifice with tip sidewards, $Q_{u}$ - discharge value through an orifice with tip upwards

\section{Conclusions}

The calculations of flow through triangle orifices, according to small and large orifice formulas, show that the differences between the two methods are very small. For every case the value of discharge calculated according to small orifice formula was bigger than the values calculated according to large orifice formula. The differences between small and large orifice discharge values decrease as the dimensions of the orifice becomes smaller, or as the submergence of the orifice becomes greater. The greatest difference between the two methods is for a triangular orifice with tip downwards, with a maximum value of around $7 \%$. For triangles with tip upwards and sidewards, the differences between discharge values calculated according to the small and large orifice formulas are around 2\% (maximum value). For an upstream head to orifice height ratio greater than 3 , it can be stated that those differences are negligible and so the discrimination of the orifices into small or large is unnecessary.

The biggest deviations in calculated values of discharge were observed for $H_{1} / h$ ratios smaller than 1 . This is due to the fact that low values of $H_{1} / h$ ratio represent low submergence levels of the orifice. This means that the layer of water over the orifice is relatively thin in relation to its dimensions. Velocity distribution in the orifice's cross section is uneven. This unevenness depends on the orifice submergence: with the growth of submergence level, the distribution of velocity in the cross section of the orifice becomes more uniform. This relationship also explains the greatest differences of discharge calculations for the triangle with tip downwards. 
The orientation of an orifice does not affect the result of the calculation. The differences between the flow values obtained by small or large orifice formulas for all cases of orifice orientation remain at only a few per cent. For the majority of triangular orifice discharge cases, the small orifice formula can be used and it will not be encumbered with an error of significant value.

The differences between the two formulas are not influenced by the variable dimensions of the orifice. The conclusions apply to triangular orifices that are equilateral, as well as isosceles.

\section{References}

Mitosek M. (2020) Fluid mechanics in environmental engineering and protection, Oficyna Wydawnicza Politechniki Warszawskiej, Warszawa (In Polish).

Shammaa Y., Zhu D.Z. and Rajaratnam N. (2005) Flow Upstream of Orifices and Sluice Gates, Journal of Hydraulic Engineering, ASCE 131 (2), 127-133.

Smith D. and Walker W. J. (1923) Orifice flow, Proc., Institution of Mechanical Engineers, 1 (1), 23-36.

Stefański W. and Wyszkowski K. (1972) Tablice $i$ wykresy do obliczeń z hydrauliki mechaniki cieczy $i$ gazów (Tables and graphs for calculations in hydraulics mechanics of liquids and gases), Wydawnictwa Politechniki Warszawskiej, Warszawa.

Vatankhah A. R. and Mirnia S. H. (2018) Predicting Discharge Coefficient of Triangular Side Orifice under Free Flow Conditions, Journal of Irrigation and Drainage Engineering, 144 (10), October 2018.

Vatankhah A. R. and Bijankhan M. (2013) Discussion of "New method for modeling thin walled orifice flow under partially submerged conditions" by David Brandes and William T. Barlow, J. Irrig. Drain. Eng., 139 (9), 789-793, https://doi.org/10.1061/(ASCE)IR.1943-4774.0000584. 